\title{
Analisis Tingkat Ketahanan Pangan Terhadap Kerawanan Pangan Menggunakan Metode GIS (Geographic Information System)
}

\section{Analysis of Food Security Levels to Food Valuity Using GIS (Geographic Information System)}

\author{
Mulono Apriyanto ${ }^{1 *}$ Dan Rujiah ${ }^{2}$
}

${ }^{1}$ Universitas Islam Indragiri, Indragiri Hilir

${ }^{2}$ Dinas Pertanian Tanaman Pangan Hortikultura dan Peternakan Kabupuaten Indragiri Hilir

*E-mail : mulonoapriyanto71@gmail.com

\begin{abstract}
The purpose of this study was to analyze the distribution of food security levels against food insecurity using the GIS (Geographic Information System) method. This research was conducted using a survey method during February and June 2019, located in Indragiri Hilir Regency. The data used are indicators of food security, indicators of food access, and indicators of food utilization. To know the distribution of data resistance levels, it is analyzed using Geographical Information Systems (GIS). The results showed that the distribution of food security levels in the twenty sub-districts in Indragiri Hilir Regency had various conditions including food insecurity, somewhat food insecurity, sufficient food resistance, food resistance, and very food resistance. \% of stunted children and (\%) the ratio of health workers are indicators that affect the level of food security and food insecurity. The study concluded that the distribution of food security levels among sub-districts in Indragiri Hilir Regency has conditions, among others, somewhat food insecurity, food resistance, sufficient food resistance, and very food resistance. Percentage of stunted children and the ratio of health workers affect on the level of food insecurity as indicators of food security)
\end{abstract}

Keywords: Food Insecurity, Food Security, Geographic Information System,

Disubmit : 21 Februari 2021; Diterima: 22 Maret 2021; Disetujui : 15 April 2021

\section{PENDAHULUAN}

Undang-Undang No. 18 Tahun 2012, Pangan adalah segala sesuatu yang berasal dari sumber hayati produk pertanian, perkebunan, kehutnan, perikanan, peternakan, perairan dan air, baik yang diolah maupun tidak diolah yang diperuntukkan sebagai makanan dan minuman bagi konsumsi manusia, termasuk bahan tambahan pangan, bahan baku pangan, dan bahan lainya yang digunakan dalam proses penyiapan, pengolahan, dan pembuatan makanan atau minuman (Apriyanto, Marlina and Arpah, 2020; Ramli and Apriyanto, 2020). Food and Agriculture Organization (FAO), tahun 2002 menyatakan ketahanan pangan adalah kondisi tersedianya pangan yang memenuhi kebutuhan setiap orang baik dalam jumlah maupun mutu pada setiap saat untuk hidup sehat, aktif dan produktif. Dua faktor yang mempengaruhi sistem pangan saat ini yaitu faktor internal dan eksternal yang mengubah secara cepat ke dalam kondisi rawan Pangan. (Mulyo, Sugiyarto and Widada, 2015; Saliem and Ariani, 2016; Riadinata, Zakaria and Murniati, 2020).

Pada dasarnya kerawanan pangan dan kelaparan disebabkan masalah kekurangan pangan antara lain akibat (Hartono, 2020) : (1) rendahnya ketersediaan pangan, (2) gangguan distribusi karena kerusakan sarana 
dan prasarana serta keamanan distribusi, (3) terjadinya bencana alam menyebabkan suatu wilayah terisolasi, (4) kegagalan produksi pangan, serta (5) gangguan kondisi sosial. Kerawanan pangan suatu daerah diidentifikasi dari jumlah penduduk miskin. Hartono (2020), menginformasikan bahwa penduduk miskin Kabupaten Indragiri Hilir tahun 2016 dan 2107 sebanyak 315.98 jiwa dan 368.13 jiwa. Prosentase penduduk miskin Kabupaten Indragiri Hilir tahun 2018 dan 2019 sebesar 7.05 dan $6.24 \%$. Menurut Hartono, (2020) Tahun 2018 Kecamatan dengan prosentase penduduk miskin tertinggi dan terrendah adalah Kecamatan Tembilahan dan Teluk Belengkong, yaitu sebesar 12,04\% dan 1,36 \%. Prosentase penduduk miskin tahun 2018 tertinggi $(5,97 \%)$ terjadi di Kecamatan Kempas, dan terrendah terdapat di Kecamatan Teluk Blengkong, yaitu sebesar $1,36 \%$. Guna mendata, menganalisa dan menentukan suatu daerah termasuk daam daerah rawan pangan atau tahan pangan. Analisa data tersebut dapat digunakan aplikasi computer yaitu Sistem Informasi Geogafis.

Sistem Informasi Geografis (SIG) adalah sistem perangkat lunak komputer, perangkat keras dan data, personel yang memungkinkan untuk memasukkan, memanipulasi, menganalisis, dan menyajikan data, serta informasi yang terikat pada suatu lokasi di permukaan bumi. Sistem ini terdiri dari Perangkat Lunak, Perangkat Keras, Data, dan Personalia yang memungkinkan untuk memasukkan, memanipulasi, menganalisis, dan menyajikan informasi yang terkait dengan suatu lokasi di permukaan bumi (Husein, 2003; Chang, 2014; Ali, 2020).

\section{METODE PENELITIAN}

Penelitian ini menggunakan data sekunder yang dikumpulkan dari perantara atau secara tidak langsung yang berupa buku, catatan, bukti yang telah ada, atau arsip baik yang dipublikasikan maupun yang tidak dipublikasikan secara umum. Data hasil penelitian tingkat ketahanan pangan terhadap kerawanan pangan akan dianalisa menggunakan metode analisis SIG. Analisis SIG akan dihasilkan peta tingkat ketahanan pangan terhadap kerawanan pangan di Kabupaten Indragiri Hilir.

\section{HASIL DAN PEMBAHASAN Ketersediaan Pangan}

Ketersediaan pangan adalah kondisi tersedianya pangan dari hasil produksi dalam negeri, cadangan pangan, serta pemasukan pangan, termasuk didalamnya bantuan pangan. Produksi pangan meliputi produksi tanaman pangan seperti sereal dan umbi-umbian, kacang-kacangan, biji minyak, sayuran dan buah-buahan serta peternakan dan perikanan. Beras adalah makanan pokok bagi sebagian besar masyarakat Kabupaten Indragiri Hilir. Luas panen padi pada tahun 2015 sebesar 29.769 Ha dengan produkai 111.315 ribu ton GKG. Selain pangan pokok utama beras, jagung, ubi kayu dan ubi jalar, bahan pangan lainnya masih dikonsumsi oleh sebagian masyarakat, seperti sagu. Produksi Padi di Kabupaten Indragiri Hilir tahun 2015 untuk padi sawah dan padi ladang berturut - turut sebesar 111.318 dan 949.19 ton (Apriyanto, Arpah and Junaidi, 2019; Riadinata, Zakaria and Murniati, 2020).

Tabel 1. Jumlah Produksi Padi dan Produksi Netto Beras Menurut Kecamatan Di Kabupaten Indragiri Hilir Tahun 2018

\begin{tabular}{clcccc}
\hline \multirow{2}{*}{ No } & \multicolumn{1}{c}{ Kecamatan } & Produksi GKG* & $\begin{array}{c}\text { Produkssi } \\
\text { Netto beras }\end{array}$ & $\begin{array}{c}\text { R net** } \\
(\text { Ton })\end{array}$ & $\begin{array}{c}\text { Persentase } \\
(\%)\end{array}$ \\
\hline 1 & Keritang & 2393,84 & 15077.06 & 14674.50 & 26.04 \\
2 & Kemuning & 949,19 & 597.99 & 582.02 & 1.03 \\
3 & Reteh & 14163,71 & 8923.14 & 8684.89 & 15.41 \\
4 & Sungai Batang & 9887,17 & 6228.92 & 6062.61 & 10.76 \\
5 & Enok & 447,89 & 282.17 & 274.64 & 0.49 \\
6 & Tanah Merah & 0 & 0 & 0 & 0 \\
7 & Kuala Indragiri & 177,7 & 111.95 & 108,96 & 0.19 \\
8 & Concong & 17,45 & 10.99 & 10,70 & 0.02 \\
\hline
\end{tabular}

Hal 55 Volume 5 Nomor 1,Tahun, 2021 


\begin{tabular}{clcccc}
\hline 9 & Tembilahan & 6156,08 & 3878.33 & 3774,78 & 6.70 \\
10 & Tembilahan Hulu & 8418,97 & 5303.95 & 5162,34 & 9.16 \\
11 & Tempuling & 7437,64 & 4685.71 & 4560,60 & 8.09 \\
12 & Batang Tuaka & 8818,94 & 5555.93 & 5407,59 & 9.60 \\
13 & Kempas & 22627,54 & 1425.40 & 1387,34 & 2.46 \\
14 & Gaung Anak Serka & 1174,11 & 739.69 & 719,94 & 1.28 \\
15 & Gaung & 8055,96 & 5075.25 & 4939,75 & 8.77 \\
16 & Mandah & 0 & 0 & 0 & 0 \\
17 & Kateman & 0 & 0 & 0 & 0 \\
18 & Pelangiran & 0 & 0 & 0 & 0 \\
19 & Teluk Belengkong & 0 & 0 & 0 & 0 \\
20 & Pulau Burung & 0 & 0 & 0 & 0 \\
\hline \multicolumn{2}{r}{ Jumlah } & 91899.19 & 57896.49 & 56350.65 & 100 \\
\hline
\end{tabular}

*GKG = Gabah Kering Giling **Rnet = Produksi Netto Beras (Ton)

Sumber: hasil penelitian

Produksi Netto Beras di Kabupaten Indragiri Hilir mencapai 57.896,49 ton, dengan nilai konversi penggunaan produksi padi untuk tercecer dan pakan ternak yaitu sebesar 5,4\% dan 0,44\%, sehingga netto pada beras (Rnet) adalah sebanyak 56.350,65 ton. Rasio antara konsumsi pangan normatif dengan ketersediaan ini sekaligus merupakan ukuran yang menunjukkan proporsi dari ketersediaan yang digunakan untuk konsumsi. Rasio konsumsi normatif terhadap ketersediaan pangan serelia di Kabupaten Indragiri Hilir pada tahun 2018 menunjukan nilai 0,043 (Riadinata, Zakaria and Murniati, 2020).

Indeks Komposit (NCRF) terhadap ketersediaan pangan Serealia dapat diperoleh berdasarkan perhitungan produksi netto bersih pangan serealia dengan perhitungan kebutuhan konsumsi normatif (300 $\mathrm{gr} / \mathrm{kapita} / \mathrm{hari}$ ) guna dapat mencapai standar kebutuhan kalori sebesar $2.000 \mathrm{kkal} / \mathrm{kapita} / \mathrm{hari}$ (Muharun and Apriyanto, 2014; Suryanti, Apriyanto and Nadia, 2017; Apriyanto and Rujiah, 2018). Berdasarkan Gambar 1 hal ini menunjukkan bahwa secara keseluruhan pada Tahun 2019 Kabupaten Indragiri Hilir berada dalam kondisi sangat tahan pangan. Namun dari 20 Kecamatan yang di analisis terdapat 1 kecamatan dengan kategori sangat rawan pangan yaitu Kecamatan Pelangiran dan kategori cukup tahan pangan terdapat pada 3 kecamatan yaitu Kecamatan Mandah, Concong dan Kateman.

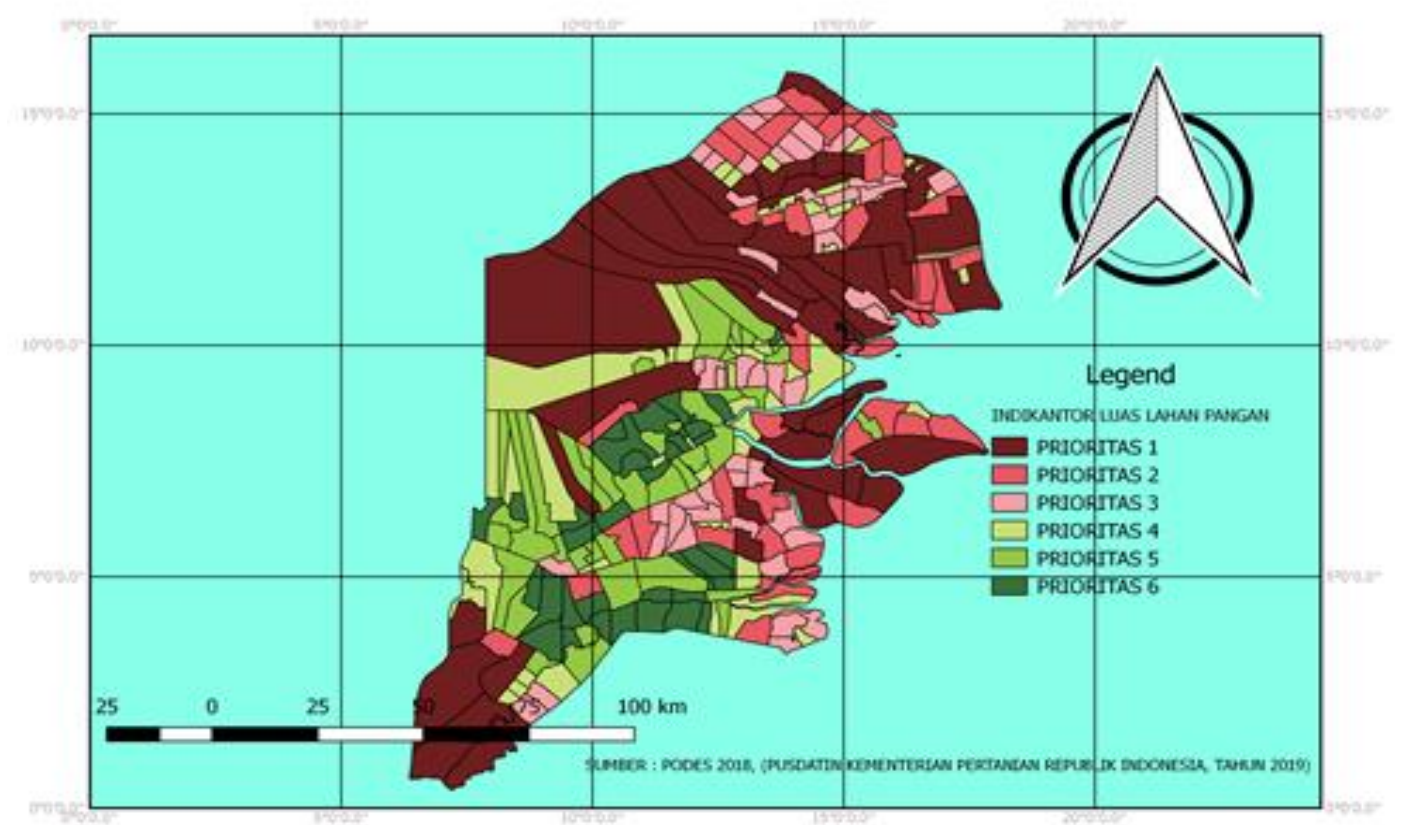

Gambar 1. Peta Indikator Luas Lahan Pangan Kabupaten INHIL Berdasar Analisis GIS Tahun 2019 
Keterangan:

\begin{tabular}{ccc}
\hline Prioritas & Skor & Keterangan \\
\hline 1 & $\geq 0,80$ & Sangat Rawan Pangan \\
2 & $0,64-<0,80$ & Rawan Pangan \\
3 & $0,48-<0,64$ & Agak Rawan Pangan \\
4 & $0,32-<0,48$ & Cukup Tahan Pangan \\
5 & $0,16-<0,32$ & Tahan Pangan \\
6 & $\leq 0,16$ & Sangat Tahan Pangan \\
\hline
\end{tabular}

Hal ini disebabkan karena ketersediaan pangan serealia di ketiga kecamatan ini belum dapat memenuhi standar kebutuhan konsumsi normatif, dimana standar kebutuhan konsumsi normattif sebesar 300 gram/kapita/hari. Enam belas kecamtan di Kabupaten Indragiri Hilir ini termasuk dalam klasifikasi sangat tahan pangan, tahan pangan, dan cukup tahan pangan (Apriyanto, Mardesci and Rujiah, 2020). Hal ini menunjukkan bahwa ketersediaan pangan serealia di 16 kecamatan, sudah memenuhi ketersediaan pangan serealia yang harus dikonsumsi oleh setiap masyarakatnya. Peta indikator luas lahan pangan menunjukan bahwa beberapa kecamatan dan desa masuk dalam indikator $1-3$, lebih besar dibandingkan desa yang masuk katagori $4-6$. Hal ini disebabkan beberapa kecamatan mempunyai luas lahan tanaman pangan yang kecil serta kondisi tanahnya kurang memenuhi untuk tanaman pangan.

\section{Pemanfaatan Pangan}

Pemanfaatan pangan terdiri dari lima bagian yaitu akses air bersih dan akses penduduk terhadap fasilitas kesehatan $>5 \mathrm{~km}$. Air bersih merupakan kebutuhan yang sangat penting bagi rumah tangga dalam kehidupan sehari-hari. persentase tertinggi yaitu 2,41\% rumah tangga tidak memiliki akses terhadap air bersih dan layak minum (air ledeng, air hujan, sumur terlindung/sumur bor/mata air) dengan jarak ke tempat penampungan akhir tinja lebih dari $10 \mathrm{~m}$ (tidak termasuk air kemasan). Peta indikator desa tidak memiliki akses air minum memadai berdasarkan analisis FSVA di kabupaten Indragiri Hilir dapat dilihat pada Gambar 2.

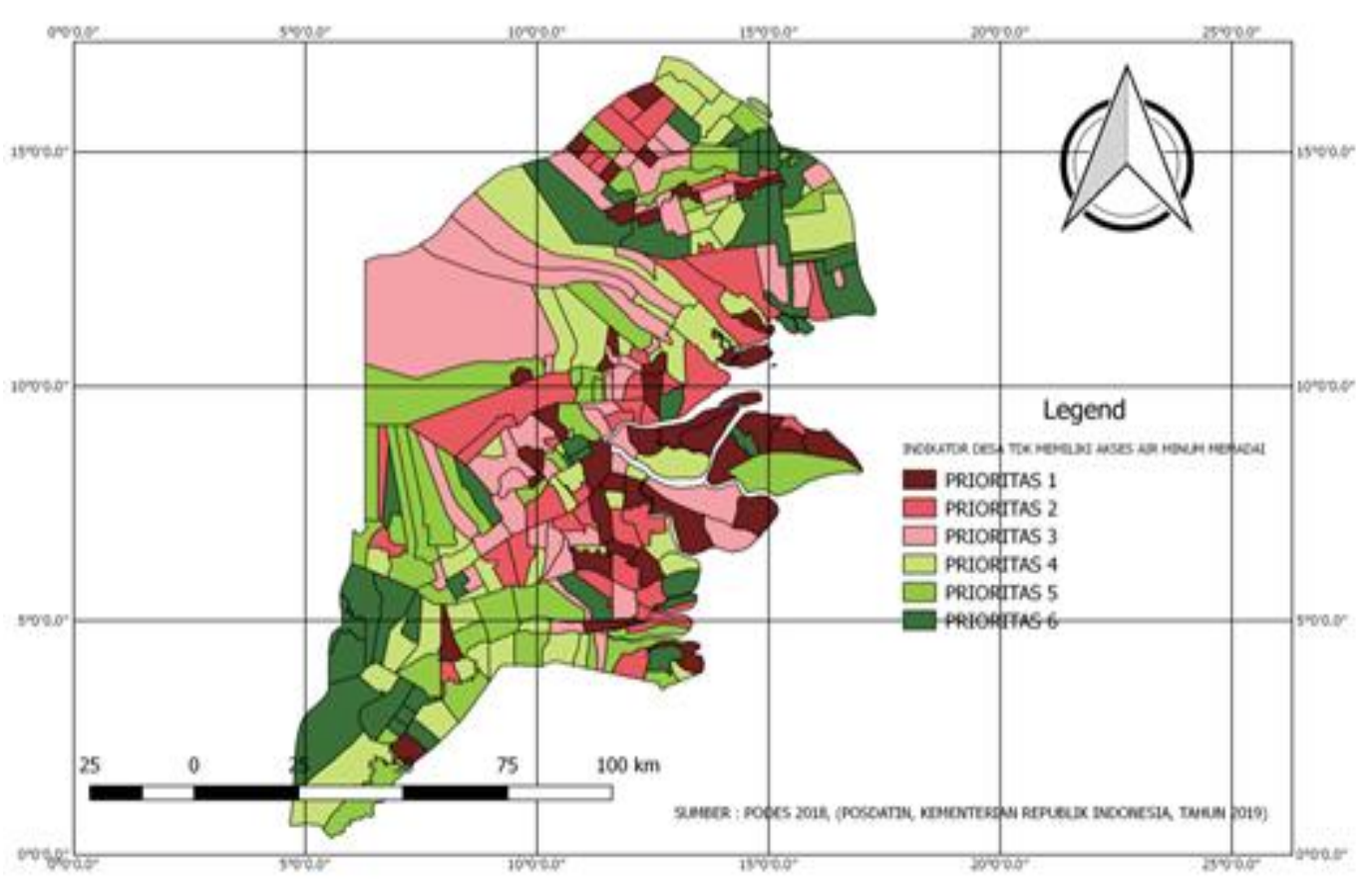

Gambar 2. Peta Indikator Desa Tidak Memiliki Air Minum Memadai Berdasarkan Analisis GIS Tahun 2019 
Keterangan :

\begin{tabular}{ccc}
\hline Prioritas & Skor & Keterangan \\
\hline 1 & $\geq 0,80$ & Sangat Rawan Pangan \\
2 & $0,64-<0,80$ & Rawan Pangan \\
3 & $0,48-<0,64$ & Agak Rawan Pangan \\
4 & $0,32-<0,48$ & Cukup Tahan Pangan \\
5 & $0,16-<0,32$ & Tahan Pangan \\
6 & $\leq 0,16$ & Sangat Tahan Pangan \\
\hline
\end{tabular}

Prosentase rumah tangga tidak memiliki akses terhadap air bersih terrendah $0.27 \%$ di miliki Kecamatan Teluk Belengkong. Dilihat dari indeks air bersih ada tiga kecamatan dalam kondisi sangat tahan pangan yaitu Kecamatan Teluk Belengkog, Pulau Burung dan Keritang. Sumber air minum yang layak sangat penting untuk menjaga kesehatan masyarakat, terutama anak-anak (Dewan, Ketahanan, 2015; Amalina, Binasasi and Purnaweni, 2018).

Akses air bersih memegang peranan yang sangat penting untuk pencapaian ketahanan pangan. Air yang tidak bersih akan meningkatkan risiko terjadinya sakit dan kemampuan dalam menyerap makanan dan pada akhirnya akan mempengaruhi gizi seseorang. Rasio tenaga kesehatan terhadap jumlah penduduk digunakan sebagai indikator untuk mengukur ketersediaan tenaga kesehatan guna mencapai target pembangunan kesehatan tertentu. Kecamatan Tembilahan dengan penduduk 75.854 jiwa dilayani oleh 55 orang dokter sehingga rasionya 1 orang dokter melayani 2000 jiwa. Tenaga kesehatan yang banyak dimiliki setiap kecamatan adalah bidan sebanyak 1.137 orang. Jadi berdasarkan rasio jumlah tenaga kesehatan di kecamatan dapat diketahui indeks ketersediaan tenaga kesehatan tiap kecamatan (Hartono, 2020).

Kecamatan Enok dan Teluk Belengkong yaitu sebesar 2,68\%. Sedangkan yang terendah terdapat di Kecamatan Concong. Kemudian jika dilihat kondisi antar kecamatan terhadap rasio tenaga kesehatan di Kabupaten Indragiri Hilir terdapat 3 kecamatan dalam kondisi agak rawan, 1 kecamatan dalam kondisi sangat rawan, 6 kecamatan dalam kondisi cukup tahan pangan, 10 kecamatan berada kondisi tahan pangan. Perhitungan ratio ini adalah dengan menggunakan konstanta perkalian 100.000, dengan rumus Jumlah tenaga tertentu dibagi jumlah penduduk kali 100.000. Dokter umum di Kabupaten Indragiri Hilir tahun 2018 sebanyak 87 orang sedangkan jumlah penduduk 629.841 ribu jiwa, berarti 1 (satu) dokter terbebani sekitar delapan ribu penduduk. Peta indikator tenaga kesehatan berdasarkan analisis GIS di kabupeten Indragiri hilir dapat dilihat pada Gambar 3.

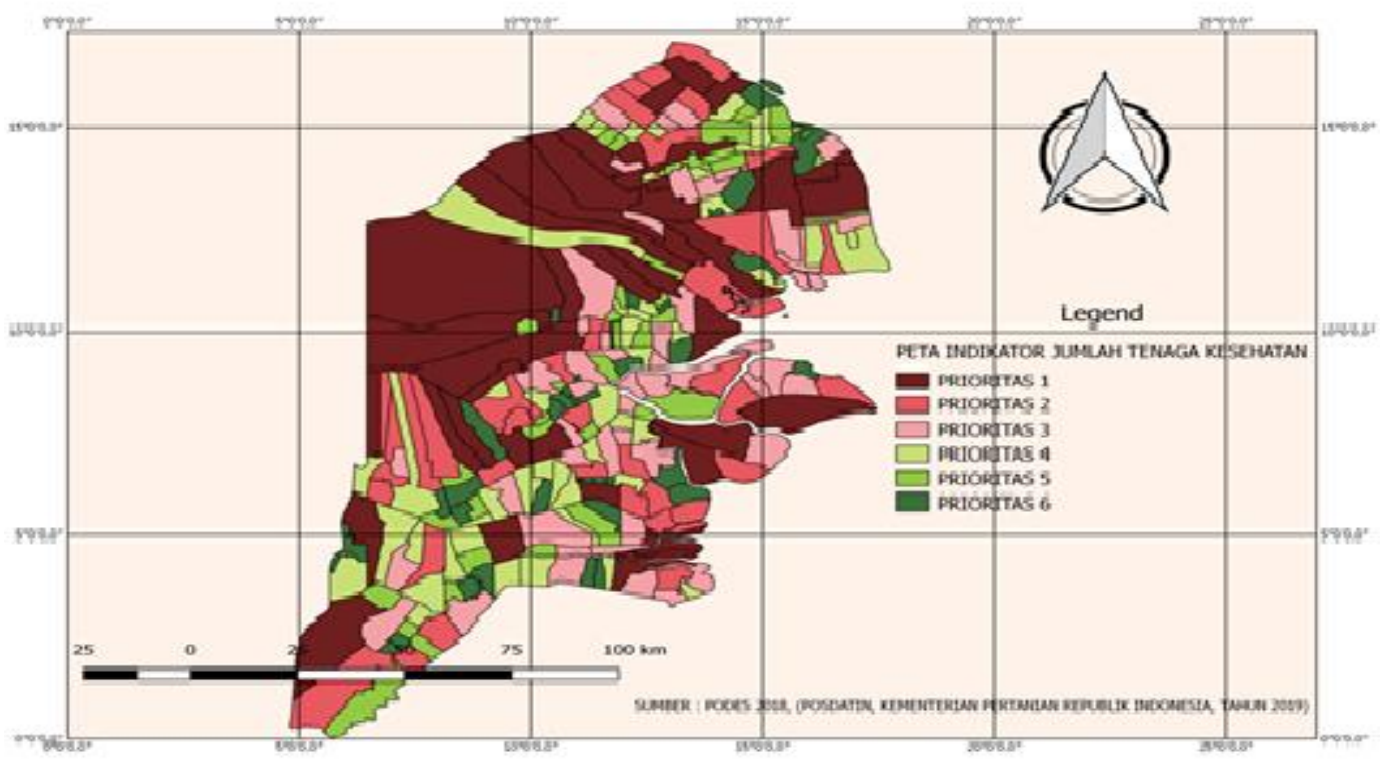

Gambar 3. Peta Indikator tenaga kesehatan tahun 2019 
Keterangan :

\begin{tabular}{ccc}
\hline Prioritas & Skor & Keterangan \\
\hline 1 & $\geq 0,80$ & Sangat Rawan Pangan \\
2 & $0,64-<0,80$ & Rawan Pangan \\
3 & $0,48-<0,64$ & Agak Rawan Pangan \\
4 & $0,32-<0,48$ & Cukup Tahan Pangan \\
5 & $0,16-<0,32$ & Tahan Pangan \\
6 & $\leq 0,16$ & Sangat Tahan Pangan \\
\hline
\end{tabular}

\section{Kerawanan Pangan (Indeks Komposit Kerawanan Pangan)}

Kerawanan pangan adalah suatu kondisi ketidakcukupan pangan yang dialami daerah, masyarakat, atau rumah tangga, pada waktu tertentu untuk memenuhi standar kebutuhan fisiologi bagi pertumbuhan dan kesehatan masyarakat. Indeks Komposit Kerawanan Pangan Menurut Kecamatan di Kabupaten Indragiri Hilir, Tahun 2019 disajikan Gambar 4.

Dari hasil Gambar 4 dapat diketahui bahwa dari 20 kecamatan yang ada di Kabupaten Indragiri Hilir berada pada kondisi yang beragam diantaranya kondisi rawan pangan, agak rawan pangan, cukup tahan pangan, tahan pangan dan sangat tahan pangan. 20 Kecamatan di Kabupaten Indragiri Hilir yang berada dalam kondisi rawan pangan terdapat pada Kecamatan Pelangiran, kemudian kecamatan yang berada pada kondisi agak rawan pangan yaitu Kecamatan Teluk Belengkong, Kateman, Mandah, Gaung dan Keritang selanjutnya kecamatan yang berada di kondisi cukup tahan pangan yaitu Kecamatan Gaung Anak Serka, Batang Tuaka, Kempas, Tempuling, Tembilahan Hulu, Tanah Merah, Enok, Sungai Batang, Reteh dan Kemuning.

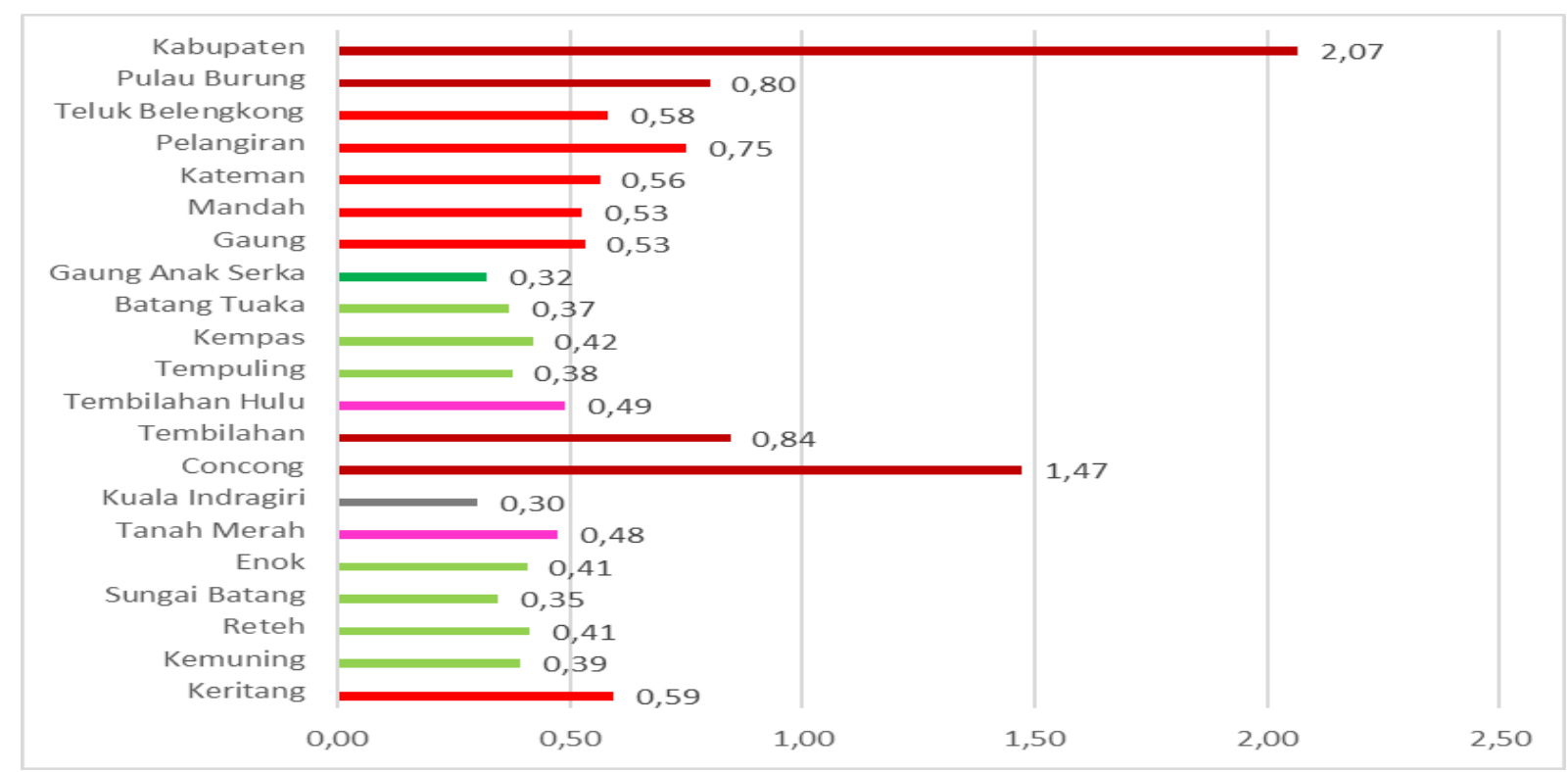

Gambar 4. Indeks Komposit Kerawanan Pangan Per Kecamatan di Kabupaten Indragiri Hilir, Tahun 2019 Keterangan :

\begin{tabular}{ccc}
\hline Prioritas & sekor & Keterangan \\
\hline 1 & $\geq 0,80$ & Sangat Rawan Pangan \\
2 & $0,64-<0,80$ & Rawan Pangan \\
3 & $0,48-<0,64$ & Agak Rawan Pangan \\
5 & $0,32-<0,48$ & Cukup Tahan Pangan \\
6 & $0,16-<0,32$ & Tahan Pangan \\
\hline
\end{tabular}




\section{KESIMPULAN}

Sebaran tingkat ketahanan pangan di Kabupaten Indragiri Hilir terdiri kondisi agak rawan pangan yaitu Kecamatan Teluk Belengkong, Kateman, Mandah, Gaung dan Keritang selanjutnya kecamatan yang berada di kondisi cukup tahan pangan yaitu Kecamatan Gaung Anak Serka, Batang Tuaka, Kempas, Tempuling, Tembilahan Hulu, Tanah Merah, Enok, Sungai Batang, Reteh dan Kemuning. Beberapa Kecamatan dalam kondisi sangat tahan pangan yaitu Tembilahan dan Pulau burung. Kecamatan mempunyai kondisi sangat rawan pangan yaitu Pelangiran.

\section{DAFTAR PUSTAKA}

Ali, E. (2020) 'Geographic Information System ( GIS ): Definition, Development, Applications \& Components', in Department of Geography, Ananda Chandra College, Jalpaiguri, pp. 1-12.

Amalina, A., Binasasi, S. D. and Purnaweni, H. (2018) 'Formulasi Kebijakan Perlindungan Lahan Pertanian Pangan Berkelanjutan Di Kabupaten Karawang', Gema Publica, 3(2), p. 92. doi: 10.14710/gp.3.2.2018.92-102.

Apriyanto, M., Arpah, M. and Junaidi, A. (2019) 'Analisis Kesiapan Petani Swadaya dalam Menghadapi Rancangan Peraturan Presiden No. 44 Tahun 2020 Tentang Pengelolaan Kelapa Sawit Berkelanjutan Ditinjau dari Aspek Status Lahan, Legalitas dan Sumber Bibit Di Kabupaten Indragiri Hilir', Jurnal Teknologi Pertanian, 8(1), pp. 38-48.

Apriyanto, M., Mardesci, H. and Rujiah, R. (2020) 'Perubahan Asam Asetat, Total Polifenol dan Warna Biji Kakao Asalan Selama Fermentasi’, Jurnal Industri Hasil Perkebunan, 15(1), pp. 10-16.

Apriyanto, M., Marlina and Arpah, M. (2020) 'Perbanyakan Tanaman Secara Vegetatif Di Desa Pekan Kamis Kelurahan Tembilahan Barat', Celebes Abdimas: Jurnal Pengabdian Kepada Masyarakat, 2(1), pp. 42-46.

Apriyanto, M. and Rujiah, R. (2018) 'Penurunan total polifenol, etanol, asam laktat, asam asetat, dan asam amino selama fermentasi biji kakao asalan dengan penambahan inokulum', Jurnal Gizi dan Dietetik Indonesia (Indonesian Journal of Nutrition and Dietetics), 5(1), pp. 1-8. doi: 10.21927/ijnd.2017.5(1).1-8.

Chang, K.-T. (2014) 'Introduction to Geographic Information System', Sri Lanka College of Microbiologists Bulletin 12(1), 12(1), pp. 33-37.

Dewan, Ketahanan, P. (2015) 'Peta Ketahanan dan Kerentanan Pangan Indonesia 2015: Versi Rangkuman'.

Hartono (2020) Kabupaten Indragiri Hilir Dalam Angka 2020, BPS Kabupaten Indragiri Hilir.

Husein, R. (2003) 'Konsep Dasar Sistem Informasi Geografis (Geographics Information System)', in Komunitas eLearning IlmuKomputer.Com, pp. 1-9.

Muharun, M. and Apriyanto, M. (2014) 'Pengolahan Minyak Kelapa Murni (Vco) Dengan Metode Fermentasi Menggunakan Ragi Tape Merk Nkl', Jurnal Teknologi Pertanian, 3(2), pp. 9-14. doi: 10.32520/jtp.v3i2.69.

Mulyo, J. H., Sugiyarto and Widada, A. W. (2015) 'Ketahanan dan Kemandirian Pangan Rumah Tangga Tani Daerah Marginal Di Kabupaten Bojonegoro’, Agro Ekonomi, 26(2), pp. 121-128.

Ramli, M. and Apriyanto, M. (2020) 'Manajemen Keuangan untuk Meningkatkan Perekonomian Keluarga Di Masa Pandemi COVID-19', Sellodang Mayang, 6(3), pp. 145-152. 
Riadinata, C., Zakaria, W. A. and Murniati, K. (2020) 'Analisis Usahatani Padi Petani Peserta dan Non Peserta Lumbung Pangan Masyarakat ( LPM ) Di Kabupaten Pringsewu Analysis For Rice Farm of Participants Farmers and Non-Participants Farmers of Community Food Barn ( LPM ) In Pringsewu District', Journal of Food System and Agribusiness, 4(2), pp. 92-98.

Saliem, H. P. and Ariani, M. (2016) 'Ketahanan Pangan, Konsep, Pengukuran dan Strategi', Forum penelitian Agro Ekonomi, 20(1), p. 12. doi: 10.21082/fae.v20n1.2002.12-24.

Suryanti, S. D., Apriyanto, M. and Nadia, L. S. (2017) 'Pengaruh Lama Pemeraman dan Jenis Kertas Pembungkus Terhadap Kualitas Sifat Organoleptik dan Kimia Buah Pisang Ambon (Musa paradisiaca var. sapientum L)', Jurnal Teknologi Pertanian, 6(1), pp. 26-37. 